\title{
Risk factors for astigmatic components and internal compensation: the Nanjing Eye Study
}

\author{
Zijin Wang ${ }^{1} \cdot$ Haohai Tong ${ }^{1} \cdot$ Qingfeng Hao ${ }^{1} \cdot$ Xuejuan Chen ${ }^{1} \cdot$ Hui Zhu ${ }^{1} \cdot$ Dan Huang ${ }^{1} \cdot$ Rui Li $^{1} \cdot$ Zhibin Hu $^{2,3} \cdot$ \\ Hu Liu ${ }^{1}$
}

Received: 4 November 2019 / Revised: 3 April 2020 / Accepted: 7 April 2020 / Published online: 22 April 2020

(c) The Author(s) 2020. This article is published with open access

\begin{abstract}
Purpose To determine the risk factors for total astigmatism (TA), anterior corneal astigmatism (ACA), and internal compensation in Chinese preschool children.

Methods In the population-based Nanjing Eye Study, children were measured for noncycloplegic refractive error and for biometric parameters. Data from questionnaires and measures from right eyes were analyzed for determining risk factors for TA, ACA, and internal compensation from multivariate logistic regression models.

Results Of 1327 children $(66.8 \pm 3.4$ months, 53.2\% male), older age of the child $(\mathrm{OR}=0.95$ for per month increase; $P=0.03)$, older paternal age at child birth $(\mathrm{OR}=1.04$ for per year increase; $P=0.03)$, paternal astigmatism $(\mathrm{OR}=1.89 ; P=0.003)$, maternal astigmatism $(\mathrm{OR}=1.73, P=0.008)$, and second-hand smoke exposure during pregnancy $(\mathrm{OR}=1.64 ; P=0.03)$ were associated with higher risk of TA, while partial breastfeeding $(\mathrm{OR}=0.49, P=0.006)$ or formula feeding $(\mathrm{OR}=0.46, P=0.003)$ were associated with lower risk of TA. Larger ratio of axial length to corneal radius $(\mathrm{OR}=16.16$ for per unit increase; $P=0.001)$, maternal working during pregnancy $(\mathrm{OR}=1.27 ; P=0.04)$, and cesarean delivery $(\mathrm{OR}=1.68, P=0.04)$ were associated with higher risk of ACA, while formula feeding was associated with lower risk of ACA $(\mathrm{OR}=0.57, P=0.01)$. Paternal astigmatism $(\mathrm{OR}=0.50, P=0.01)$ and assisted reproduction $(\mathrm{OR}=0.56, P=$ 0.03 ) were associated with lower risk of horizontal or vertical internal compensation. More outdoor activity time (OR $=1.15$ for per hour increase, $P=0.01$ ) was associated with higher risk of oblique internal compensation while more nighttime sleep on weekends $(\mathrm{OR}=0.83$ for per hour increase, $P=0.01$ ) was associated with lower risk of oblique internal compensation. Conclusions Our study confirmed some previously reported risk factors and identified some novel risk factors for astigmatism including formula feeding for lower risk of both ACA and TA, and older paternal age at child birth for higher risk of TA.
\end{abstract}

These authors contributed equally: Zijin Wang, Haohai Tong, Qingfeng Hao

Supplementary information The online version of this article (https:// doi.org/10.1038/s41433-020-0881-5) contains supplementary material, which is available to authorized users.

Zhibin $\mathrm{Hu}$

zhibin_hu@njmu.edu.cn

$\triangle \mathrm{Hu}$ Liu

liuhu@njmu.edu.cn

1 Department of Ophthalmology, The First Affiliated Hospital with Nanjing Medical University, 300 Guangzhou Road, 210029

Nanjing, China

\section{Introduction}

Astigmatism is an important clinical and public health problem; If uncorrected, astigmatism can lead to continuous blurred vision at any distance.

Previous studies have found many factors associated with astigmatism including high risk genes, eyelid pressure, extraocular muscle tension, gestational age, birth weight,

2 State Key Laboratory of Reproductive Medicine, Nanjing Medical University, 101 Longmian Street, 211166 Nanjing, China

3 Department of Epidemiology and Biostatistics, Jiangsu Key Lab of Cancer Biomarkers, Prevention and Treatment, Collaborative Innovation Center for Cancer Personalized Medicine, School of Public Health, Nanjing Medical University, 101 Longmian Street, 211166 Nanjing, China 
nutrition [1], ethnicity, spherical equivalent refractive error, maternal smoking during pregnancy [2], accommodative convergence/accommodation ratio (AC/A) [3], age, education, ametropia [4], the axial length-corneal radius ratio (AL/CR) [5], delivery mode [6], socio-economically deprivation [7] and iris color [8]. In a recent paper on 48-60-month-old Chinese children [9], we reported the prevalence of the components of astigmatism, described the difference between corneal astigmatism (CA) and anterior corneal astigmatism (ACA), and demonstrated the compensatory role of internal astigmatism (IA) in reducing ACA. In addition, we evaluated the role of age, gender, and $\mathrm{AL} / \mathrm{CR}$ on the components of astigmatism. However, our study did not evaluate the other potential risk factors as these data were not collected. During ongoing Nanjing Eye Study (NES), we collected additional potential risk factors, particularly the factors during pregnancy and early childhood, a critical period for the development of refractive error $[10,11]$. Furthermore, previous studies only evaluated risk factors for total astigmatism (TA) and CA. As we already demonstrated the compensatory role of IA, analysis for risk factors of internal compensation may lead to new discoveries and help build the overall framework of astigmatic genesis and development.

This study was to perform a comprehensive evaluation of potential risk factors for TA, ACA, and internal compensation in a large population-based NES.

\section{Materials and methods}

\section{Study population}

The NES is an ongoing population-based open cohort study, designed to longitudinally observe the onset and progression of childhood ocular diseases in eastern China $[9,12-15]$. The study was approved by the institutional review board in The First Affiliated Hospital with Nanjing Medical University and was conducted in accordance with the tenets of the Declaration of Helsinki. Written consent was obtained from the parents or guardians of all children. The study population for the present study consisted of 61-72-month-old children enrolled in kindergarten in the Yuhuatai District of Nanjing City in East China and born between September 2011 and August 2012. Data from eye examinations and questionnaire presented in this paper were collected in 2017.

\section{Eye examination}

Six experienced ophthalmologists and four optometrists specialized in pediatric eye care performed comprehensive eye examinations following the standard study protocol.
The noncycloplegic refractive status of both eyes of each participant was measured using an autorefractor (Cannon RF10; Canon, Tokyo, Japan). The optic low-coherent reflectometer (LenStar LS-900; Haag-Streit AG, Koeniz, Switzerland) was used to obtain biometric parameters, including corneal curvatures and axial length. The examining procedure has been described in detail previously [9].

A comprehensive questionnaire was distributed to legal guardians of each child. The questionnaire collected data including basic information of children and parents, history of pregnancy, birth, feeding status, daily activities within the past year, sleep quality within the past month, home environment, and guardian's concerns over eyes. We calculated average daily hours spent on activities classified as near-work activities, mid-working distance activities, and outdoor activities. The 5-min Apgar score at birth was categorized as normal $(\geq 7)$ and abnormal $(<7)$.

\section{Definition}

Astigmatism was defined as a cylinder magnitude worse than or equal to 1.0 diopter (D), expressed as a negative cylinder form. The magnitude of ACA was calculated as the difference between the flattest and steepest corneal meridians of the anterior corneal surface with the cylindrical axis equal to the flattest meridian. The magnitude of IA was calculated as the vectorial difference between TA and ACA. The presence of TA was defined as TA equal to -1 or less, and the presence of ACA was defined as ACA equal to -1 or less. To decompose TA and ACA, the vector method modified by Thibos [16] was used for the following calculations:

$$
\begin{aligned}
& S E=S+C / 2, \\
& J_{0}=(-C / 2) \times(\cos 2 A), \\
& J_{45}=(-C / 2) \times(\sin 2 A),
\end{aligned}
$$

where $S E$ is the spherical equivalent, $S$ is sphere, $C$ is the cylinder in minus format, $A$ is the cylinder axis, $J_{0}$ and $J_{45}$ are the horizontal or vertical and oblique vectors of the cylinder, respectively. According to these methods, $J_{0 \mathrm{t}}, J_{0 \mathrm{a}}$, and $J_{0 \mathrm{i}}$ were calculated, representing $J_{0}$ of TA, ACA, and IA respectively. Similar calculations were made for $J_{45}$, $J_{45 \text { a }}$, and $J_{45 \mathrm{i}}$.

The compensation factor (CF) was calculated as the negative ratio of IA and ACA. $J_{0}$ and $J_{45}$ were used to evaluate $\mathrm{CF}$ as following:

$$
\begin{aligned}
& C F_{0}=-J_{0 i} / J_{0 a}, \\
& C F_{45}=-J_{45 i} / J_{45 a} .
\end{aligned}
$$


The compensation types were classified as following based on the calculated CF $[9,17,18]$. The presence of internal compensation was defined as $\mathrm{CF} 0.1-2$. If $\mathrm{CF}<0.1$ or $\mathrm{CF}>$ 2 , it was categorized as without internal compensation.

$\mathrm{AL} / \mathrm{CR}$ was calculated as the axial length (mm) divided by the mean radius of curvature $(\mathrm{mm})$.

\section{Statistical analysis}

The Statistical Package for the Social Sciences (SPSS V.13.0; IBM, Chicago, IL, USA) was used for all statistical analyses. Results were presented as mean \pm standard deviation (SD) for continuous variables, as percentage for categorical variables. Characteristics of children included in the analysis were compared with those excluded due to missing data in questionnaire using two-sample $t$-test for comparisons of means and chi-square test for comparison of proportions. Comparisons of distribution of each candidate risk factor were performed between children with vs. without TA, between children with vs. without ACA, and between children with vs. without internal compensation using two-sample $t$-tests for continuous variables and chi-square tests for categorical variables. Multivariate logistic regression models using forward variable selection based on likelihood ratio test were performed to determine statistically significant risk factors for TA, $\mathrm{ACA}, \mathrm{CF}_{0}$, and $\mathrm{CF}_{45}$. Odds ratios (OR) and their $95 \%$ confidence intervals $(95 \% \mathrm{CI})$ were calculated from multivariate logistic regression models. All statistical tests were two-sided and $P<0.05$ was considered statistically significant.

\section{Results}

\section{Characteristics of study population}

Among 2300 eligible preschoolers, 1920 (participation rate $83.5 \%$ ) children completed comprehensive eye examinations. Among these 1920 children, 138 children were uncooperative and no refraction measurements or biometric parameters from right eye were obtained after several attempts. Guardians of 455 children did not complete the questionnaire, leaving 1327 children $(69.1 \%$ of eligible participants) included in this study. Their mean $( \pm \mathrm{SD})$ age was $66.8 \pm 3.4$ months and $706(53.2 \%)$ of participants were boys.

There were no significant differences in characteristics of children (including age, gender, prevalence rate of TA and ACA from right eyes) between children included in the analysis and those excluded from analysis due to missing data in questionnaire.

\section{Prevalence and compensation condition of astigmatism}

The prevalence rate was $12.9 \%$ (171/1327) for TA and $64.4 \%(854 / 1327)$ for ACA. CF analysis revealed that the compensation rate was $94.0 \%$ (1247/1327) in $J_{0}$, and $74.1 \%$ $(983 / 1327)$ in $J_{45}$.

\section{Risk factors}

We evaluated a total of 25 risk factors (Table 1) for TA, $\mathrm{ACA}, \mathrm{CF}_{0}$, and $\mathrm{CF}_{45}$.

Comparisons for each risk factor between children with and without TA are shown in Table 1. Children with TA were more likely to be younger $(P=0.02)$, have older father at child birth $(P=0.02)$, more likely to have myopic mothers $(P=0.048)$, astigmatic mothers or astigmatic fathers (both $P<0.001$ ) than children without TA. In the children with TA, percentage of maternal working during pregnancy $(P=0.03)$ and second-hand smoke exposure during pregnancy $(P=0.02)$ were higher than children without TA. Children with TA were also more likely to be fed with breast milk than children without TA $(P=0.02)$.

In the multivariate analysis, six risk factors were significantly independently associated with TA (Table 2): age of the child, paternal age at child birth, paternal astigmatism, maternal astigmatism, second-hand smoke exposure during pregnancy, and feeding patterns. Older age of the child was significantly associated with lower risk of TA $(\mathrm{OR}=0.95$ for per month increase; 95\% CI 0.90, 0.996), while older paternal age at child birth was associated with higher risk of TA $(\mathrm{OR}=1.04$ for per year increase; $95 \% \mathrm{CI}$ $1.004,1.07)$. Children with astigmatic fathers were 1.89 times as likely to have TA as children with non-astigmatic fathers (95\% CI 1.25, 2.86). Children with astigmatic mothers were 1.73 times as likely to have TA as children with non-astigmatic mothers (95\% CI 1.16, 2.59). Children whose mothers had second-hand smoke exposure during pregnancy were 1.64 times as likely to have TA as children whose mothers did not have second-hand smoke exposure (95\% CI 1.06, 2.54). Concerning feeding patterns, children with partial breastfeeding were 0.50 times as likely to have TA as children with exclusive breastfeeding (95\% CI 0.30 , 0.82 ), while children with formula feeding were 0.46 times as likely to have TA as children with exclusive breastfeeding (95\% CI $0.28,0.77)$.

Comparisons for each risk factor were performed between children with and without ACA (sTable 1). Children with ACA were more likely to have larger AL/CR than children without ACA $(P=0.002)$. There was significant difference between children with ACA and without ACA in delivery mode $(P=0.02)$ and feeding patterns $(P=0.02)$. 
Table 1 Distribution of risk factors in children with and without total astigmatism.

\begin{tabular}{|c|c|c|c|}
\hline Risk Factors & $\begin{array}{l}\text { Without total astigmatism } \\
(n=1156)\end{array}$ & $\begin{array}{l}\text { With total astigmatism ( } n \\
=171)\end{array}$ & $P$ value \\
\hline Mean $( \pm$ SD) age (month) & $66.92 \pm 3.42$ & $66.32 \pm 3.11$ & 0.02 \\
\hline Mean $( \pm$ SD) paternal age at child birth (year) & $27.80 \pm 4.74$ & $28.73 \pm 4.98$ & 0.02 \\
\hline Mean $( \pm$ SD) maternal age at child birth (year) & $26.16 \pm 3.94$ & $26.74 \pm 3.73$ & 0.06 \\
\hline Mean ( \pm SD) birth weight (kilogram) & $3.33 \pm 0.53$ & $3.32 \pm 0.50$ & 0.79 \\
\hline Mean $( \pm \mathrm{SD})$ near-work activity (hour) & $4.76 \pm 3.36$ & $4.80 \pm 4.80$ & 0.90 \\
\hline Mean $( \pm \mathrm{SD})$ mid-working distance activity (hour) & $1.54 \pm 1.59$ & $1.40 \pm 2.07$ & 0.38 \\
\hline Mean $( \pm \mathrm{SD})$ outdoor activity (hour) & $2.21 \pm 1.30$ & $2.34 \pm 1.70$ & 0.33 \\
\hline Mean $( \pm \mathrm{SD})$ average nighttime sleep on weekdays (hour) & $9.91 \pm 0.67$ & $9.82 \pm 0.67$ & 0.10 \\
\hline Mean $( \pm \mathrm{SD})$ average nighttime sleep on weekends (hour) & $10.21 \pm 0.86$ & $10.10 \pm 0.85$ & 0.12 \\
\hline $\mathrm{AL} / \mathrm{CR}^{\mathrm{a}}$ & $2.87 \pm 0.06$ & $2.88 \pm 0.08$ & 0.07 \\
\hline Gender: male $(\%)$ & $611(52.9 \%)$ & $95(55.6 \%)$ & 0.51 \\
\hline Paternal myopia: yes(\%) & $411(35.6 \%)$ & $68(39.8 \%)$ & 0.28 \\
\hline Maternal myopia: yes (\%) & $449(38.8 \%)$ & $80(46.8 \%)$ & 0.048 \\
\hline Paternal astigmatism yes $(\%)$ & $145(12.5 \%)$ & $40(23.4 \%)$ & $<0.001$ \\
\hline Maternal astigmatism: yes (\%) & $169(14.6 \%)$ & $43(25.1 \%)$ & $<0.001$ \\
\hline Mode of pregnancy: assisted (\%) & $188(16.3 \%)$ & $37(21.6 \%)$ & 0.08 \\
\hline Term delivery (full-term:pre-term:post-term) & & & 0.28 \\
\hline Full-term & $1042(90.1 \%)$ & $160(93.6 \%)$ & \\
\hline Pre-term & $58(5.0 \%)$ & $7(4.1 \%)$ & \\
\hline Post-term & $56(4.8 \%)$ & $4(2.3 \%)$ & \\
\hline 5-min Apgar score: Abnormal (\%) & $31(2.7 \%)$ & $9(5.3 \%)$ & 0.07 \\
\hline Delivery mode & & & 0.64 \\
\hline Vaginal & $655(56.7 \%)$ & $94(55.0 \%)$ & \\
\hline Vaginal transferring to cesarean & $91(7.9 \%)$ & $11(6.4 \%)$ & \\
\hline Cesarean & $410(35.5 \%)$ & $66(38.6 \%)$ & \\
\hline Oxygen uptake after birth: yes (\%) & $71(6.14 \%)$ & $8(4.7 \%)$ & 0.45 \\
\hline Second or third child: yes $(\%)$ & $219(18.9 \%)$ & $39(22.8 \%)$ & 0.23 \\
\hline Twin or triple: yes $(\%)$ & $25(2.2 \%)$ & $6(3.5 \%)$ & 0.41 \\
\hline Feeding patterns & & & 0.02 \\
\hline Exclusive breastfeeding & $561(48.5 \%)$ & $78(45.6 \%)$ & \\
\hline Partial breastfeeding & $493(42.6 \%)$ & $66(38.6 \%)$ & \\
\hline Formula feeding & $102(8.8 \%)$ & $27(15.8 \%)$ & \\
\hline Maternal working during pregnancy: yes (\%) & $522(45.2 \%)$ & $92(53.8 \%)$ & 0.03 \\
\hline Second-hand smoke exposure during pregnancy: yes (\%) & $143(12.4 \%)$ & $32(18.7 \%)$ & 0.02 \\
\hline
\end{tabular}

${ }^{\mathrm{a}} \mathrm{AL} / \mathrm{CR}$ : ratio of axial length to corneal radius.

The proportion of oxygen uptake after birth was higher in the children with ACA $(P=0.02)$.

In the multivariate analysis, four variables were significantly associated with ACA (Table 3): AL/CR, maternal working during pregnancy, feeding patterns, and delivery mode. Larger AL/CR was significantly associated with higher risk of $\mathrm{ACA}(\mathrm{OR}=16.63$ per unit increase; 95\% CI 3.03, 91.24). Children whose mothers working during pregnancy were 1.26 times as likely to have ACA as children whose mother stopped working during pregnancy $(95 \%$ CI 1.01, 1.59). Concerning feeding patterns, ACA was not significantly different between children with partial breastfeeding and children with exclusive breastfeeding, while children with formula feeding were 0.57 times as likely to have ACA as children with exclusive breastfeeding (95\% CI 0.37, 0.88). Concerning delivery mode, ACA was not significantly different between children born by vaginal delivery transferring to cesarean delivery and children born by vaginal delivery, while children born by cesarean delivery were 1.67 times as likely to have ACA as children born by vaginal delivery (95\% CI 1.02, 2.74). 
Table 2 Independent risk factors for total astigmatism from multivariate logistic regression.

\begin{tabular}{|c|c|c|c|}
\hline \multirow[t]{2}{*}{ Risk factors } & \multicolumn{3}{|c|}{ Multivariate analysis } \\
\hline & Adjusted OR & $95 \% \mathrm{CI}$ & $P$ \\
\hline $\begin{array}{l}\text { Month age of the child (per } \\
\text { month increase) }\end{array}$ & 0.95 & $0.90-0.996$ & 0.03 \\
\hline $\begin{array}{l}\text { Paternal age at child birth (per } \\
\text { year increase) }\end{array}$ & 1.04 & $1.004-1.07$ & 0.03 \\
\hline Paternal astigmatism (yes vs. no) & 1.89 & $1.25-2.86$ & 0.003 \\
\hline $\begin{array}{l}\text { Maternal astigmatism (yes } \\
\text { vs. no) }\end{array}$ & 1.73 & $1.16-2.59$ & 0.008 \\
\hline $\begin{array}{l}\text { Second-hand smoke exposure } \\
\text { during pregnancy (yes vs. no) }\end{array}$ & 1.64 & $1.06-2.54$ & 0.03 \\
\hline \multicolumn{4}{|l|}{ Feeding patterns } \\
\hline Exclusive breastfeeding & Reference & & \\
\hline Partial breastfeeding & 0.50 & $0.30-0.82$ & 0.006 \\
\hline Formula feeding & 0.46 & $0.28-0.77$ & 0.003 \\
\hline
\end{tabular}

$O R$ odds ratio, $C I$ confidence interval.

Table 3 Independent risk factors for anterior corneal astigmatism from multivariate logistic regression.

\begin{tabular}{llll}
\hline & \multicolumn{3}{l}{ Multivariate analysis } \\
\cline { 2 - 4 } Risk factors & Adjusted OR & $95 \%$ CI & $P$ \\
\hline AL/CR (per unit increase) & 16.63 & $3.03-91.24$ & 0.001 \\
$\begin{array}{l}\text { Maternal work during pregnancy } \\
\text { (yes vs. no) }\end{array}$ & 1.26 & $1.01-1.59$ & 0.046 \\
Feeding patterns & & & \\
Exclusive breastfeeding & Reference group & \\
Partial breastfeeding & 0.75 & $0.49-1.15$ & 0.19 \\
Formula feeding & 0.57 & $0.37-0.88$ & 0.01 \\
Delivery mode & & & \\
Vaginal delivery & Reference & & \\
Vaginal delivery transferring to & 0.86 & $0.67-1.09$ & 0.21 \\
cesarean delivery & & & \\
Cesarean delivery & 1.67 & $1.02-2.74$ & 0.04 \\
\hline
\end{tabular}

$O R$ odds ratio, $C I$ confidence interval.

Comparisons for each risk factor were performed between children with and without internal compensation (sTables 2 and 3). Children with horizontal or vertical internal compensation were more likely to have astigmatic fathers than children without horizontal or vertical internal compensation $(P=0.009)$. The percentage of assisted reproduction was lower in the children with horizontal or vertical internal compensation $(P=0.02)$. Mean outdoor activity time of children with oblique internal compensation was more than children without oblique internal compensation $(P=0.002)$. Mean average nighttime sleep on weekends was slightly less in children with oblique internal
Table 4 Independent risk factors for internal compensation from multivariate logistic regression.

\begin{tabular}{llll}
\hline & \multicolumn{3}{l}{ Multivariate analysis } \\
\cline { 2 - 4 } Risk factors & Adjusted OR & $95 \%$ CI & $P$ \\
\hline CF0 & & & \\
$\begin{array}{l}\text { Paternal astigmatism (yes vs. no) } \\
\text { Mode of pregnancy (spontaneous }\end{array}$ & 0.50 & $0.29-0.87$ & 0.01 \\
$\begin{array}{l}\text { vs. assisted) } \\
\text { CF45 }\end{array}$ & & $0.33-0.95$ & 0.03 \\
$\begin{array}{l}\text { Outdoor activity (per hour } \\
\text { increase) }\end{array}$ & 1.15 & & \\
$\begin{array}{l}\text { Sleep duration at night on } \\
\text { weekends (per hour increase) }\end{array}$ & 0.84 & $0.72-0.97-1.29$ & 0.01 \\
\hline
\end{tabular}

OR odds ratio, $C I$ confidence interval.

compensation than children without oblique internal compensation $(P=0.03)$. Mean average nighttime sleep on weekends was slightly less in children with oblique internal compensation than children without oblique internal compensation $(P=0.03)$.

In the multivariate analysis, paternal astigmatism and mode of pregnancy were significantly associated with horizontal or vertical internal compensation, while outdoor activity and sleep duration at night on weekends were significantly associated with oblique internal compensation (Table 4). Children with astigmatic fathers were 0.50 times as likely to have horizontal or vertical internal compensation as children with non-astigmatic father $(95 \%$ CI 0.29 , 0.87). Children born by assisted reproduction were 0.56 times as likely to have horizontal or vertical internal compensation as children born by spontaneous conception (95\% CI $0.33,0.95)$. More outdoor activity time (OR $=1.15$ for per hour increase, $95 \%$ CI 1.03, 1.29) was associated with higher risk of oblique internal compensation while more nighttime sleep on weekends was associated with lower risk of oblique internal compensation $(\mathrm{OR}=0.84$ for per hour increase, $95 \%$ CI 0.72, 0,97).

\section{Discussion}

Although previous studies have described the characteristics of children with astigmatism, these studies only focused on the risk factors for TA or CA. Few studies assessed risk factors for astigmatism by integrating the components of astigmatism and taking internal compensation into consideration. This study explored the risk factors of TA, ACA, and internal compensation in preschoolers. These risk factors included characteristics during pregnancy and early childhood, which were rarely studied previously for astigmatism, but important to investigate because pregnancy to early childhood is the critical time window for the 
development of refraction and were more analyzed in the spherical equivalent refraction before.

This study found that older age of the child was significantly associated with lower risk of TA but not associated with ACA. Most astigmatism, especially with-therule astigmatism, showed a trend of decreasing with age, and reached stable at 18-24 months $[10,11,19,20]$. CA tended to decrease between the age of 3 years and 8 years, but the decrease was generally small and would not be considered clinically significant [21].

This study found older paternal age at child birth was associated with higher risk of TA, which has not been reported in the literature as we know. The exact mechanism for this association is not clear. However, older paternal age at child birth has been reported to be associated with some adverse medical conditions including stillbirths, musculoskeletal syndromes, cleft palate, acute lymphoblastic leukemia, retinoblastoma, and neurodevelopmental disorders in the autism spectrum and schizophrenia [22]. Biologically, there existed nonlinear increase in germ-line mutations in males with older age [23]. Social effects could also be reasons for this association, such as the different way older fathers interact with children [24]. Further study is needed to confirm this association.

This study revealed that both paternal astigmatism and maternal astigmatism were risk factors of TA, but they were not associated with ACA. Paternal astigmatism was also associated with lower likelihood of horizontal or vertical internal compensation. Previous genetic studies on astigmatism provided contradicting results on the genetic contribution to astigmatism. Wixson concluded that both parents seemed to play roles in determining the corneal power characteristics of the child [25]. Early twin studies showed that the correlations between monozygotic twins for astigmatism were not significantly different from the correlations between dizygotic twins, which suggested that the genetic contribution to astigmatism was low [26-28]. Lee et al. found minimal association existed among family members for astigmatism [29]. However, some other twin studies suggested a genetic etiology in astigmatism development, with the estimated heritability ranging from 30 to $60 \%$ [30-34]. A meta-analysis of five Asian cohorts identifies PDGFRA as a susceptibility locus for CA [35]. Further genetic studies are needed to determine whether genetic etiology plays a role in ACA or internal compensation, which may affect the development of TA.

This study found that second-hand smoke exposure during pregnancy was associated with high risk of TA. The multi-ethnic pediatric eye disease study (MEPEDS) showed that preschool children whose mothers smoked during pregnancy were 1.5 times as likely to have astigmatism as children whose mothers did not smoke [2]. Mothers who smoked during pregnancy accounted for $8.9 \%$ in the
MEPEDS, while no mother smoked during pregnancy in our study. However, in our study, $8.9 \%$ mothers had second-hand smoke intake during pregnancy. Fetal exposure to maternal smoking is associated with numerous adverse developmental consequences during intrauterine and postnatal period. Certain biologically active substances in cigarette products, such as nicotine, cyanide, and carbon monoxide, can cross the placental barrier and induce fetal hypoxia [36]. A systematic review showed maternal smoking during pregnancy was associated with an increased risk of visual disturbances including refractive errors during childhood [37]. Both active and passive maternal smoking during pregnancy may have adverse effect on refractive error development in a dose-dependent manner [37].

Interestingly, this study showed that formula feeding reduced the risk of both TA and ACA compared with exclusive breastfeeding. Furthermore, partial breastfeeding also reduced the risk of TA compared with exclusive breastfeeding. As far as we know, none of previous studies explored the relationship between feeding patterns and astigmatism. Some previous studies suggested that infants with breastfeeding will have better vision and be less likely to be myopic in later life than those with formula feeding $[38,39]$. A study in young Singapore Chinese children showed that breastfeeding was associated with more positive spherical equivalent refraction [40]. However, another two studies did not find any significant relationship between feeding patterns and visual acuity and spherical equivalent refraction [41, 42]. Future investigations are needed to validate our finding and determine what difference between breast milk and formula might affect the development of cornea.

This study found that larger AL/CR increased the risk of ACA, but was not associated with TA. The association between AL/CR and ACA is consistent with a previous study in school children [5], and it was hypothesized that the lengthening of the AL and the shortening of the CR both could increase the pressure of the eyelids on the eye globes and ultimately lead to a corneal deformation [5].

This study revealed that cesarean section increased the risk of ACA compared with vaginal delivery, but the delivery mode was not associated with both TA and internal compensation. A previous study showed that children born by cesarean section, especially those born by elective cesarean section, were more likely to have severe TA ( $\leq$ $-2.50 \mathrm{D}$ ) compared with children born by vaginal delivery [6]. Another study revealed that at birth, neonates delivered vaginally had a greater frequency of with-the-rule CA than those delivered by cesarean section [43]. These results may be because infants delivered by cesarean section experience less or no contractions of the uterus compared with those delivered naturally. The pressure from the uterus and birth canal may contribute to changes in corneal curvature. The 
changes could also be explained by different levels of exposure from hormonal milieu of labor [6].

This study showed that children through assisted reproduction were less likely to have horizontal or vertical internal compensation than children through spontaneous conception, but the pregnancy mode was not associated with both TA and ACA. Due to special genetic background and environmental conditions, infants through assisted reproduction may be different from naturally conceived infants [44]. A study in infants born by assisted reproduction showed higher TA prevalence [44]. However, Axer-Siegel et al. found that in vitro fertilization did not affect the incidence of CA compared with spontaneous conception [45]. A study by Wikstrand did not show any significant difference in TA between children born after intra-cytoplasmic sperm injection and children born by spontaneous conception [46].

This study found that more outdoor activity time increased the likelihood of oblique internal compensation. It has been well known that outdoor activity reduces the risk of myopia [47]. Studies have found that children with myopia or hyperopia were more likely to have astigmatism than children without spherical refractive error [2, 48]. Therefore, the association between outdoor activity and astigmatic internal compensation seems reasonable. We can infer that oblique internal compensation may reduce the risk of oblique TA. Moreover, it is easier to cause amblyopia with a small degree of initial oblique astigmatism than orthogonal astigmatism $[49,50]$.

This study showed less nighttime sleep on weekends was associated with higher likelihood of oblique internal compensation. The exact mechanism for this association is unknown. Thus, future study using more precise sleep monitoring methods is needed to confirm this association.

The risk factors of TA and ACA are not completely consistent, so we can speculate that not all factors that produce change of ACA will directly lead to the change of TA. TA is not solely determined by ACA or IA, while the disturbance of internal compensation may be a possible way to cause the change of TA. The risk factors of TA, ACA, and internal compensation are different, likely due to the following reasons. First, astigmatism is a vector and vectorial decomposition may interfere with the analysis of astigmatic risk factors, but there is no better method to replace this. Second, the components of astigmatism interact with each other, so that the risk factors of astigmatic components may enhance, weaken, or offset the function of each other. Their exact mechanisms and their interactions need further study.

The strengths of this study include its population-based design, large sample size, and standardized examination protocols performed by an expert team. The age range of the subjects is relatively narrow, eliminating the impact of large age span on TA and ACA. Our analyses of risk factors for astigmatism are different from previous studies, by considering the correlation of components and internal compensation. The limitation of this study is that some eligible children were not included into the analysis due to missing data in questionnaire or refractive error measures. In addition, the risk factor data collected through questionnaire may be subjective and biased.

In summary, this study confirmed several previously reported risk factors and identified several novel risk factors for astigmatism. We found maternal astigmatism and second-hand smoke exposure during pregnancy were independent risk factors for TA; higher AL/CR, cesarean section were independent risk factors for ACA; assisted reproduction was an independent risk factor for horizontal or vertical compensation; and less outdoor activity time and more nighttime sleep on weekends were independent risk factors for oblique compensation. Compared with exclusive breastfeeding, formula feeding was associated with reduced risk in both ACA and TA. Paternal astigmatism was associated with lower risk of horizontal or vertical internal compensation and higher risk of TA. Although the novel risk factors need further validation in future studies, these new findings may help us understand the development of astigmatism and develop strategies to prevent or treat astigmatism in children.

\section{Summary}

\section{What was known before}

- Previous studies have found many factors associated with astigmatism.

- Previous studies only evaluated risk factors for total astigmatism and corneal astigmatism. Few studies assessed risk factors for astigmatism by integrating the components of astigmatism and taking internal compensation into consideration.

- Risk factors enrolled before lack characteristics during pregnancy and early childhood.

\section{What this study adds}

- Our previous study already demonstrated the compensatory role of internal astigmatism. This study explored the risk factors of total astigmatism, anterior corneal astigmatism, and internal compensation in preschoolers.

- We collected risk factors during pregnancy and early childhood.

- This study confirmed several previously reported risk factors and identified several novel risk factors for 
astigmatism including formula feeding for lower risk of both anterior corneal astigmatism and total astigmatism, and older paternal age at child birth for higher risk of total astigmatism.

Acknowledgements We thank the children, the corresponding parents or legal guardians and all the members of the Maternal and Child Healthcare Hospital of Yuhua District, Nanjing, China, for helpful advice and support.

Funding This work was supported by the National Natural Science Foundation of China (Grant No. 81673198; No. 81803258); the Natural Science Foundation of Jiangsu Province (Grant No. BK20161595); the Scientific Research Projects of Jiangsu Provincial Commission of Health and Family Planning (Grant No. H201507); Jiangsu Province's Key Provincial Talents Program (Grant No. QNRC2016563). The sponsors had no role in the design or conduct of the research.

\section{Compliance with ethical standards}

Conflict of interest The authors declare that they have no conflict of interest.

Publisher's note Springer Nature remains neutral with regard to jurisdictional claims in published maps and institutional affiliations.

Open Access This article is licensed under a Creative Commons Attribution 4.0 International License, which permits use, sharing, adaptation, distribution and reproduction in any medium or format, as long as you give appropriate credit to the original author(s) and the source, provide a link to the Creative Commons license, and indicate if changes were made. The images or other third party material in this article are included in the article's Creative Commons license, unless indicated otherwise in a credit line to the material. If material is not included in the article's Creative Commons license and your intended use is not permitted by statutory regulation or exceeds the permitted use, you will need to obtain permission directly from the copyright holder. To view a copy of this license, visit http://creativecommons. org/licenses/by/4.0/.

\section{References}

1. Read SA, Collins MJ, Carney LG. A review of astigmatism and its possible genesis. Clin Exp Optom. 2007;90:5-19.

2. McKean-Cowdin R, Varma R, Cotter SA, Tarczy-Hornoch K, Borchert MS, Lin JH, et al. Risk factors for astigmatism in preschool children: the multi-ethnic pediatric eye disease and Baltimore pediatric eye disease studies. Ophthalmology 2011;118: 1974-81.

3. Tong L, Saw SM, Carkeet A, Chan WY, Wu HM, Tan D. Prevalence rates and epidemiological risk factors for astigmatism in Singapore school children. Optom Vis Sci. 2002;79:606-13.

4. Hashemi H, Hatef E, Fotouhi A, Mohammad K. Astigmatism and its determinants in the Tehran population: the Tehran eye study. Ophthalmic Epidemiol 2005;12:373-81.

5. Wang F, Xiao L, Meng X, Wang L, Wang D. Development of Corneal Astigmatism (CA) according to Axial Length/Corneal Radius (AL/CR) Ratio in a One-Year Follow-Up of Children in Beijing, China. J Ophthalmol. 2018;2018:4209236.
6. Liu F, Yang X, Tang A, Liu L. Association between mode of delivery and astigmatism in preschool children. Acta Ophthalmol. 2018;96:e218-e221.

7. Goverdhan S, Fogarty AW, Osmond C, Lockwood A, Anderson L, Kirwan JF. Shorter axial length and increased astigmatic refractive error are associated with socio-economic deprivation in an adult UK cohort. Ophthalmic Epidemiol. 2011;18:44-7.

8. Pan $\mathrm{CW}, \mathrm{Ke} \mathrm{C}, \mathrm{Hu} \mathrm{DN}$, Li J, Zhong $\mathrm{H}$. Iris colour and astigmatism among Chinese teenagers. $\mathrm{Br} \quad \mathrm{J}$ Ophthalmol. 2019;103:1810-4.

9. Wang Z, Huang D, Chen X, Zhu H, Sun Q, Wang Y, et al. Preschool children exhibit evident compensatory role of internal astigmatism in distribution of astigmatism: the Nanjing Eye Study. Investig Ophthalmol Vis Sci. 2019;60:73-81.

10. Gwiazda J, Scheiman M, Mohindra I, Held R. Astigmatism in children: changes in axis and amount from birth to six years. Investig Ophthalmol Vis Sci. 1984;25:88-92.

11. Atkinson J, Braddick O, French J. Infant astigmatism: its disappearance with age. Vis Res. 1980;20:891-3.

12. Zhu H, Huang D, Sun Q, Ding H, Bai J, Chen J, et al. Normative visual acuity in Chinese preschoolers aged 36 to $<48$ months as measured with the linear HOTV chart: the Yuhuatai Pediatric Eye Disease Study. BMJ Open. 2017;7:e014866.

13. Huang D, Chen X, Zhu H, Ding H, Bai J, Chen J, et al. Prevalence of amblyopia and its association with refraction in Chinese preschool children aged 36-48 months. $\mathrm{Br} \mathrm{J}$ Ophthalmol. 2018;102:767-71.

14. Zhang X, Wang Y, Huang D, Sun Q, Zhao X, Ding H, et al. Prevalence of reduced visual acuity among preschool children in eastern China and comparison at a 5-year interval. Clin Exp Ophthalmol. 2018;46:994-1001.

15. Han S, Zhang X, Zhao X, Wang Y, Hao Q, Li R, et al. Stereoacuity and related factors in healthy preschool children: the Nanjing Eye Study. Ophthalmic Epidemiol. 2019;26:336-44.

16. Thibos LN, Wheeler W, Horner D. Power vectors: an application of Fourier analysis to the description and statistical analysis of refractive error. Optom Vis Sci. 1997;74:367-75.

17. Park CY, Oh JH, Chuck RS. Predicting ocular residual astigmatism using corneal and refractive parameters: a myopic eye study. Curr Eye Res. 2013;38:851-61.

18. Liu Y, Cheng Y, Zhang Y, Zhang L, Zhao M, Wang K. Evaluating internal and ocular residual astigmatism in Chinese myopic children. Jpn J Ophthalmol. 2017;61:494-504.

19. Mayer DL, Hansen RM, Moore BD, Kim S, Fulton AB. Cycloplegic refractions in healthy children aged 1 through 48 months. Arch Ophthalmol. 2001;119:1625-8.

20. Ehrlich DL, Braddick OJ, Atkinson J, et al. Infant emmetropization: longitudinal changes in refraction components from nine to twenty months of age. Optom Vis Sci. 1997;74:822-43.

21. Harvey EM, Miller JM, Schwiegerling J, Sherrill D, Messer DH, Dobson V. Developmental changes in anterior corneal astigmatism in Tohono O'odham Native American infants and children. Ophthalmic Epidemiol. 2013;20:102-8.

22. Nybo Andersen AM, Urhoj SK. Is advanced paternal age a health risk for the offspring? Fertil Steril. 2017;107:312-8.

23. Crow JF. Development. There's something curious about paternal-age effects. Science. 2003;301:606-7.

24. Petersen L, Mortensen PB, Pedersen CB. Paternal age at birth of first child and risk of schizophrenia. Am J Psychiatry. 2011;168:82-8.

25. Wixson RJ. Refraction pedigrees. 2. The cornea. Am J Optom Arch Am Acad Optom. 1965;42:615-8.

26. Teikari JM, O’Donnell JJ. Astigmatism in 72 twin pairs. Cornea. 1989;8:263-6. 
27. Teikari J, O’Donnell JJ, Kaprio J, Koskenvuo M. Genetic and environmental effects on oculometric traits. Optom Vis Sci. 1989;66:594-9.

28. Valluri S, Minkovitz JB, Budak K, et al. Comparative corneal topography and refractive variables in monozygotic and dizygotic twins. Am J Ophthalmol. 1999;127:158-63.

29. Lee KE, Klein BE, Klein R, Fine JP. Aggregation of refractive error and 5-year changes in refractive error among families in the Beaver Dam Eye Study. Arch Ophthalmol. 2001;119: 1679-85.

30. Dirani M, Islam A, Shekar SN, Baird PN. Dominant genetic effects on corneal astigmatism: the genes in myopia (GEM) twin study. Investig Ophthalmol Vis Sci. 2008;49:1339-44.

31. Grjibovski AM, Magnus P, Midelfart A, Harris JR. Epidemiology and heritability of astigmatism in Norwegian twins: an analysis of self-reported data. Ophthalmic Epidemiol. 2006;13:245-52.

32. Hammond CJ, Snieder H, Gilbert CE, Spector TD. Genes and environment in refractive error: the twin eye study. Invest Ophthalmol Vis Sci. 2001;42:1232-6.

33. Yeh LK, Chiu CJ, Fong CF, Wang IJ, Chen WL, Hsiao CK, et al. The genetic effect on refractive error and anterior corneal aberration: twin eye study. J Refract Surg. 2007;23:257-65.

34. Cagigrigoriu A, Gregori D, Cortassa F, Catena F, Marra A. Heritability of corneal curvature and astigmatism: a videokeratographic child-parent comparison study. Cornea. 2007;26:907-12.

35. Fan Q, Zhou X, Khor CC, Cheng CY, Goh LK, Sim X, et al. Genome-wide meta-analysis of five Asian cohorts identifies PDGFRA as a susceptibility locus for corneal astigmatism. PLoS Genet. 2011;7:e1002402.

36. Werler MM. Teratogen update: smoking and reproductive outcomes. Teratology. 1997;55:382-8.

37. Fernandes M, Yang X, Li JY, Cheikh Ismail L. Smoking during pregnancy and vision difficulties in children: a systematic review. Acta Ophthalmol. 2015;93:213-23.

38. Chong YS, Liang Y, Tan D, Gazzard G, Stone RA, Saw SM. Association between breastfeeding and likelihood of myopia in children. JAMA. 2005;293:3001-2.

39. American College of Obstetricians and Gynecologists Women's Health Care Physicians; Committee on Health Care for Underserved Women. Committee Opinion No.570: breastfeeding in underserved women: increasing initiation and continuation of breastfeeding. Obstet Gynecol. 2013;122:423-8.

40. Sham WK, Dirani M, Chong YS, Hornbeak DM, Gazzard G, Li J, et al. Breastfeeding and association with refractive error in young Singapore Chinese children. Eye. 2010;24:875-80.

41. Shirzadeh E, Kooshki A, Mohammadi M. The relationship between breastfeeding and measurements of refraction and visual acuity in primary school children. Breastfeed Med. 2016;11:235-8.

42. Rudnicka AR, Owen CG, Richards M, Wadsworth ME, Strachan DP. Effect of breastfeeding and sociodemographic factors on visual outcome in childhood and adolescence. Am J Clin Nutr. 2008;87:1392-9.

43. Isenberg SJ, Del Signore M, Chen A, Wei J, Christenson PD. Corneal topography of neonates and infants. Arch Ophthalmol. 2004;122:1767-71.

44. Jafarzadehpur E, Kermani RM, Mohhamadi AR, Nateghi MR, Fazeli AS, Kashi KM. Ocular manifestations in infants resulted from assisted reproductive technology (ART). J Fam Reprod Health. 2013;7:181-6.

45. Axer-Siegel R, Bourla D, Sirota L, Weinberger D, Snir M. Ocular growth in premature infants conceived by in vitro fertilization versus natural conception. Investig Ophthalmol Vis Sci. 2005;46:1163-9.

46. Wikstrand MH, Strömland K, Flodin S, Bergh C, Wennerholm UB, Hellström A. Ophthalmological findings in children born after intracytoplasmic sperm injection. Acta Ophthalmol Scand. 2006;84:177-81.

47. Morgan IG, French AN, Ashby RS, Guo X, Ding X, He M, et al. The epidemics of myopia: aetiology and prevention. Prog Retin Eye Res. 2018;62:134-49.

48. Huang J, Maguire MG, Ciner E, Kulp MT, Cyert LA, Quinn GE, et al. Risk factors for astigmatism in the vision in preschoolers study. Optom Vis Sci. 2014;91:514-21.

49. Moghaddam AA, Kargozar A, Zarei-Ghanavati M, Najjaran M, Nozari V, Shakeri MT. Screening for amblyopia risk factors in pre-verbal children using the Plusoptix photoscreener: a crosssectional population-based study. Br J Ophthalmol. 2012;96:83-6.

50. Chou YS, Tai MC, Chen PL, Lu DW, Chien KH. Impact of cylinder axis on the treatment for astigmatic amblyopia. Am J Ophthalmol. 2014;157:908-14. 